\title{
Polarized Raman spectra of $L$-arginine hydrochloride monohydrated single crystal
}

\author{
J.L.B. Faria \\ Departamento de Física, Universidade Federal de Mato Grosso, Cuiabá-MT, 78060-900, Brazil \\ P.T.C. Freire, ${ }^{*}$ R.O. Gonçalves, F.E.A. Melo, and J. Mendes Filho \\ Departamento de Física, Universidade Federal do Ceará, Fortaleza-CE, 60455-760, Brazil \\ R.J.C. Lima, A.J.D. Moreno \\ Centro de Ciências Sociais, Saúde e Tecnologia, Universidade Federal do Maranhão, Imperatriz-MA, 65900-410, Brazil
}

(Received on 16 October, 2009)

\begin{abstract}
Polarized Raman spectra of $L$-arginine hydrochloride monohydrated single crystal in nine different scattering geometries of the two irreducible representations of factor group $C_{2}$ were studied at room temperature. The experimental wavenumber values are compared with those obtained from ab-initio calculation and the assignment of the Raman bands to the respective molecular vibrations is also given. Finally, a discussion related to a previously reported phase transition undergone by $L$-arginine hydrochloride monohydrated single crystal at low temperature is furnished.
\end{abstract}

Keywords:

\section{INTRODUCTION}

Amino acids $\left(\mathrm{NH}_{2}-\mathrm{CH}-\mathrm{COOH}-\mathrm{R}\right.$, where $\mathrm{R}$ is a radical) are the basic units of proteins and peptides of all living beings. For an unknown reason Nature has choose 20 of these special molecules, differing in the $R$ part, to form the impressive number of proteins found in our planet. $L$ arginine, among other amino acids, and its salts, including $L$ arginine $\mathrm{HCl}$, is known to protect protein from inactivation in frozen solutions, during freeze-drying [1], during spraydrying [2] and in the storage of lyophilized solids [3]. Beyond this, $L$-arginine and acid combinations have been extensively used in the last years to assist in the recovery of chemically unfolded proteins and recombinant proteins expressed in inclusion bodies [4].

Beyond these biological aspects related to amino acid in general, and $L$-arginine in particular, it is also possible to found interesting physical properties related to this amino acid. For example, the search for new non-linear optical materials with high non-linear coefficients and high damage threshold has lead to the discovery of $L$-arginine phosphate monohydrate (LAP) [5]. These studies also allowed the discovery of new materials having $L$-arginine as the main substance. Among these material is $L$-arginine hydrochloride monohydrate (LAHW) whose several physical properties as thermal expansion, elastic properties and dielectric characteristics were presented in Ref. [6].

Some works deal with the temperature behavior of $L$ arginine $\cdot \mathrm{HCl} \cdot \mathrm{H}_{2} \mathrm{O}$ monocrystals. It was observed that under high temperature conditions LAHW begins to lost water of crystallization at $70^{\circ} \mathrm{C}$ and at $200^{\circ} \mathrm{C}$ about two-third of it are eliminated [7]. Under low temperature conditions, on the other hand, it was observed through Raman scattering technique, evidence of a phase transition undergone by LAHW between 100 and $110 K$ [8]. Although in the paper of Ref. [8] some Raman spectra are presented, up to now, there is no

*Electronic address: tarso@fisica.ufc.br complete investigation of the polarized Raman spectra for LAHW, as well as, an assignment of the observed modes. Such assignment is very important because it helps us to understand what vibrations are related to the crystal modifications, in particular under temperature and pressure changes.

The objective of this paper is twofold: (i) to present the Raman spectra in the spectral region $20-3700 \mathrm{~cm}^{-1}$ for nine scattering geometries of the two irreducible representations of the $C_{2}$ factor group; (ii) to give a tentative assignment of the observed Raman bands based on ab-initio calculations.

\section{EXPERIMENTAL}

Single crystals of $L A H C L$ were grown from aqueous solution containing $L$-arginine hydrochloride powder, $\mathrm{C}_{6} \mathrm{H}_{14} \mathrm{~N}_{4} \mathrm{O}_{2} \cdot \mathrm{HCl}$, from Sigma by the slow evaporation method at controlled temperature $(293 K)$. In order to characterize and to do the orientation of the crystals we used X-ray diffraction patterns obtained from a Rigaku DMAX diffractometer using $\mathrm{Cu} \mathrm{K \alpha}$ radiation monochromated with a graphite crystal. The Raman spectra were obtained with a Jobin Yvon T64000 micro-Raman system equipped with an $\mathrm{N}_{2}$-cooled charge coupled device system. The samples were polished with diamond paste with granulations with 10,3 and $1 \mu \mathrm{m}$. The slits were set for a $2 \mathrm{~cm}^{-1}$ spectral resolution. Excitation was effected with the $514.5 \mathrm{~nm}$ radiation from an argon ion laser. The incident laser had a power less than $5 \mathrm{~mW}$ on the surface of the sample.

\section{RESULTS AND DISCUSSION}

Fig. 1 presents the zwitterion form of an arginine molecule (the number associated to the atoms will be used in the assignment of the normal modes). Single crystal data of LAHW crystal confirms that the compound grows with a monoclinic lattice belonging to the $P 2_{1}\left(C_{2}^{2}\right)$ space group with two molecules of arginine $\left(\mathrm{C}_{6} \mathrm{H}_{14} \mathrm{O}_{2} \mathrm{~N}_{4}\right)$, two units of $\mathrm{HCl}$ and two units of $\mathrm{H}_{2} \mathrm{O}$ per unit cell. In the primitive cell 
Table 1. Wavenumbers $\left(\mathrm{cm}^{-1}\right)$ and tentative assignment for the bands appearing in the Raman spectra of LAHW crystal at room temperature. The notation $a(b c) d$ is the conventional Porto notation, where $a$ and $d$ represent the directions of the incident and the scattered light and $b$ and $c$ represent the directions of polarizations of the incident and the scattered light.

\begin{tabular}{|c|c|c|c|c|c|c|c|c|c|c|c|}
\hline \multirow{2}{*}{$\begin{array}{c}v(\mathrm{~cm}-1) \\
\text { Calculate }\end{array}$} & \multicolumn{2}{|c|}{ Base Set } & \multicolumn{9}{|c|}{ scattering geometries } \\
\hline & $6-311++\mathrm{G}^{* *}$ & $6-311 G$ & $\mathrm{x}(\mathrm{yy}) \mathrm{x}$ & $\mathrm{z}(\mathrm{yy}) \mathrm{z}$ & $y(x x) y$ & $\mathrm{z}(\mathrm{xx}) \mathrm{z}$ & $\mathrm{x}(\mathrm{zz}) \mathrm{x}$ & $\mathrm{y}(\mathrm{zz}) \mathrm{y}$ & $\mathrm{x}(\mathrm{yz}) \mathrm{z}$ & $\mathrm{z}(\mathrm{yx}) \mathrm{z}$ & $\mathrm{y}(\mathrm{zx}) \mathrm{y}$ \\
\hline 44 & & & & & 43 & 43 & 41 & 43 & 42 & 43 & \\
\hline 48 & $\tau$ (N17-C19) & & & & & & & & & & \\
\hline 57 & & & 59 & 59 & 60 & 59 & 58 & 59 & 58 & 59 & 61 \\
\hline \multirow[t]{2}{*}{61} & $\mathrm{r}\left(\mathrm{NH}_{3}^{+}\right)$ip & & 63 & 63 & & 63 & 61 & 63 & 62 & 63 & \\
\hline & & & 68 & 68 & 71 & 71 & 69 & 70 & 68 & 70 & 71 \\
\hline 78 & & r(H16-C15-H18) & 75 & 75 & 85 & 75 & 74 & 75 & 74 & 75 & 77 \\
\hline \multirow[t]{5}{*}{86} & r(H16-C15-H18) & & & 87 & & 83 & 85 & 87 & & 86 & \\
\hline & & & 94 & & 96 & 96 & 95 & 96 & 95 & 96 & 90 \\
\hline & & & 105 & 102 & 102 & 102 & 101 & 102 & 105 & 102 & 100 \\
\hline & & & & & & 109 & 106 & 106 & & & 106 \\
\hline & & & 120 & 120 & 118 & 118 & 117 & 119 & 118 & 119 & 119 \\
\hline 131 & & r(H13-C12-H14) & & & & & & & & & 132 \\
\hline \multirow[t]{2}{*}{137} & r(H13-C12-H14) & & 142 & 142 & 140 & 141 & 138 & 139 & 141 & 142 & \\
\hline & & & & & & & 149 & 151 & & & 152 \\
\hline \multirow[t]{2}{*}{163} & w(C15-N17-C19) & r(N1-H7-H26) & 158 & 159 & 159 & 162 & 156 & 158 & 158 & 162 & \\
\hline & & & 185 & 190 & 189 & 189 & 189 & 192 & & 189 & 191 \\
\hline 237 & $\tau\left(\mathrm{NH}_{3}^{+}\right)$ & & 244 & 245 & 243 & 245 & 243 & 243 & 243 & 244 & \\
\hline 261 & r(H10-C9-H11) & & & & & & & & & & \\
\hline 262 & & r(H10-C9-H11) & 268 & 273 & 269 & 274 & 267 & 270 & & 273 & \\
\hline 305 & $\delta$ (C9-C12-C15) & & 307 & 307 & 306 & 307 & 303 & 303 & 305 & 307 & 303 \\
\hline \multicolumn{12}{|l|}{308} \\
\hline 326 & & & & & & & & & & & 321 \\
\hline 327 & $\tau$ (skel.) & & & & & & & & & & \\
\hline \multirow[t]{2}{*}{334} & & $\tau\left(\mathrm{NH}_{3}^{+}\right)$ & & & 331 & & 331 & 332 & 335 & & \\
\hline & & & 340 & 340 & 341 & 340 & & & & 340 & 340 \\
\hline 389 & & & 377 & 378 & 378 & 379 & 377 & 377 & 380 & 378 & \\
\hline 394 & $\delta(\mathrm{C} 3-\mathrm{C} 2-\mathrm{N} 1)$ & & & & & & & & & & \\
\hline \multirow[t]{2}{*}{415} & & & & & & & & & & 415 & \\
\hline & & & 419 & 417 & & & 419 & 418 & 422 & & 425 \\
\hline 446 & $\mathrm{r}_{1}\left(\mathrm{NH}_{2}\right)$ & $\mathrm{r}_{1}\left(\mathrm{NH}_{2}\right)$ & 446 & 446 & & 448 & 445 & 447 & 446 & 447 & \\
\hline 457 & $\mathrm{r}_{2}\left(\mathrm{NH}_{2}\right)$ & & 466 & 466 & 465 & 465 & & & & 465 & 470 \\
\hline 513 & & $\delta(\mathrm{N} 17-\mathrm{H} 20)$ & & 529 & 531 & & 532 & 533 & 533 & 530 & 535 \\
\hline 545 & $\delta$ (N17-C19-N22) & & 539 & & & 537 & & & & 539 & \\
\hline 557 & $v(\mathrm{C} 2-\mathrm{C} 3-\mathrm{N} 1)$ & & 551 & 553 & 550 & 551 & & & 552 & 552 & \\
\hline \multicolumn{12}{|l|}{558} \\
\hline 567 & $\delta$ (C2-C9-C12) & & & & & & & & & & \\
\hline 585 & $\delta$ (N17-C19-N21) & & 621 & 620 & & & 618 & 619 & 619 & 621 & 619 \\
\hline 625 & & & & & & & & & 629 & & \\
\hline 670 & $v(\mathrm{C} 2-\mathrm{C} 3)$ & & 678 & 679 & & 679 & 675 & 678 & 677 & 678 & \\
\hline
\end{tabular}

of LAHW, all the atoms occupy sites with symmetry $C_{1}$ and the 186 vibrations can be decomposed into the irreducible representations of the factor group $C_{2}$ as $\Gamma=93 A+93 B$, with one $A$ and two $B$ belonging to the acoustic branch and all the other being Raman and infra red active. In Figs. $2-5, Z$ represents an axis parallel to the [001] direction, $X$ represents an axis parallel to the [100] direction and $Y$ is an axis perpendicular to the $X$ and $Z$ axes.

In order to give insights about the assignment of the normal modes of the crystal we have performed $a b$ initio calculations. All calculations were carried out using Gaus- sian98 (by computational resources in CENAPAD's facilities) and the results were viewed by MOLEKEL programme packages. Geometry optimization and frequency calculation for $L$-arginine in the gas phase were performed with SelfConsistent methods and Hartree-Fock (HF) level of theory, with $6-31+G(d, p)$ and $6-311++G(d, p)$ basis sets. The molecular framework was designed in Gchempaint (gnome chemical software packages) and the atomic coordenates of isolated $l$-arginine was used in input file. This structure was optimized using $\delta E<10^{-8}$ as convergence parameter and the vibrational wavenumbers were then calculated. The out- 


\begin{tabular}{|c|c|c|c|c|c|c|c|c|c|c|c|}
\hline \multirow{2}{*}{$\begin{array}{l}v(\mathrm{~cm}-1) \\
\text { Calculate }\end{array}$} & \multicolumn{2}{|c|}{ Base Set } & \multicolumn{9}{|c|}{ scattering geometries } \\
\hline & $6-311++\mathrm{G}^{* *}$ & 6-311G & $x(y y) x$ & $\mathrm{z}(\mathrm{yy}) \mathrm{z}$ & $\mathrm{y}(\mathrm{xx}) \mathrm{y}$ & $\mathrm{z}(\mathrm{xx}) \mathrm{z}$ & $\mathrm{x}(\mathrm{zz}) \mathrm{x}$ & $\mathrm{y}(\mathrm{zz}) \mathrm{y}$ & $\mathrm{x}(\mathrm{yz}) \mathrm{z}$ & $\mathrm{z}(\mathrm{yx}) \mathrm{z}$ & $\mathrm{y}(\mathrm{zx}) \mathrm{y}$ \\
\hline 692 & & & 701 & 702 & & 702 & 700 & 701 & 700 & 702 & \\
\hline 717 & $\begin{array}{l}\mathrm{w}(\mathrm{N} 21-\mathrm{C} 19-\mathrm{N} 17- \\
\mathrm{N} 22)\end{array}$ & & & & & & & & & & \\
\hline 732 & w(N17-C19-N22) & & 751 & 753 & 751 & & & & 748 & 753 & \\
\hline 786 & $\tau$ (skel.) & & 784 & 784 & 782 & 782 & & & 783 & 783 & 777 \\
\hline 799 & & & & & & & & & & & \\
\hline 829 & & & & & & & & & & & \\
\hline 831 & & & & 831 & 831 & 830 & & & & 830 & \\
\hline 846 & $\delta\left(\mathrm{CO}_{2}^{-}\right)$ & & 843 & 843 & 843 & 843 & 842 & 843 & 842 & 843 & 841 \\
\hline 885 & & & & & & & & & & & \\
\hline 890 & & $\delta(\mathrm{N} 21-\mathrm{H} 23)$ & & 892 & 897 & 898 & 890 & 892 & 890 & 892 & 891 \\
\hline 894 & $\mathrm{r}\left(\mathrm{NH}_{3}^{+}\right)$op & & 897 & 898 & & & 897 & 898 & 897 & 898 & 898 \\
\hline 900 & & & & & & & & & & & \\
\hline 902 & & & & & & & & & & & \\
\hline 904 & & & & & & & & & & & \\
\hline 929 & $\mathrm{w}\left(\mathrm{NH}_{2}\right)$ & & 930 & 931 & 931 & 930 & 929 & 930 & 930 & 930 & 930 \\
\hline & & & 939 & 940 & 939 & 939 & 939 & 939 & 939 & 940 & 940 \\
\hline 950 & & & 955 & & & & 953 & 955 & & & \\
\hline 957 & & & 960 & 960 & 959 & 959 & 958 & 959 & 958 & 959 & 957 \\
\hline 1001 & $\mathrm{r}_{1}{ }^{\prime}\left(\mathrm{NH}_{3}{ }^{+}\right)$op & & & & & & & & & & \\
\hline 1006 & & & & & & & & & & & \\
\hline & & & 1029 & 1029 & 1027 & 1028 & 1028 & 1029 & 1029 & 1021 & 1029 \\
\hline & & & 1049 & 1049 & 1049 & 1049 & 1049 & 1049 & 1049 & 1050 & \\
\hline 1053 & $v(\mathrm{C} 2-\mathrm{N} 1)$ & & 1052 & 1053 & 1059 & 1052 & & & 1052 & & \\
\hline 1073 & & & & 1062 & & 1059 & 1060 & 1060 & & 1057 & 1064 \\
\hline 1096 & $\mathrm{r}_{1}\left(\mathrm{NH}_{3}{ }^{+}\right)$op & & 1089 & 1092 & 1092 & 1090 & 1090 & 1090 & 1093 & 1091 & \\
\hline & & & 1099 & 1100 & 1099 & 1099 & 1100 & 1101 & 1099 & 1099 & 1101 \\
\hline 1112 & & $\delta_{1}(\mathrm{~N} 1-\mathrm{H} 26)$ & & & & & & & & & \\
\hline & & & & 1132 & 1134 & 1135 & & & & 1136 & 1133 \\
\hline 1120 & $\mathrm{r}_{2}{ }^{\prime}\left(\mathrm{NH}_{3}{ }^{+}\right)$op & & & & & & & & & & \\
\hline 1144 & & $\mathrm{w}(\mathrm{N} 1-\mathrm{H} 5-\mathrm{H} 26)$ & 1139 & & & & 1138 & 1138 & 1140 & & 1142 \\
\hline 1163 & $v(\mathrm{C} 19-\mathrm{N} 22)$ & & & & & & & & & & \\
\hline 1172 & & $\delta$ 2(N1-H26) & & & & & & & & & \\
\hline 1180 & $\mathrm{r}_{2}\left(\mathrm{NH}_{3}{ }^{+}\right)$op & & 1179 & 1181 & 1177 & 1179 & 1176 & 1178 & 1179 & 1180 & 1179 \\
\hline 1211 & $\mathrm{r}_{1}{ }^{\prime \prime}\left(\mathrm{NH}_{3}{ }^{+}\right)$op & $\mathrm{w}\left(\mathrm{NH}_{3}{ }^{+}\right)$ & & & & & & & & & \\
\hline 1231 & & & & & & & 1231 & 1232 & & & \\
\hline 1247 & $\mathrm{r}_{2}{ }^{\prime \prime}\left(\mathrm{NH}_{3}{ }^{+}\right)$op & & 1253 & & & & 1250 & 1250 & 1253 & & 1253 \\
\hline 1257 & $\mathrm{t}_{1}\left(\mathrm{NH}_{2}\right)$ & & & & & & & & & & \\
\hline 1259 & & $\mathrm{r}_{2}\left(\mathrm{NH}_{2}\right)$ & & & & & & & & & \\
\hline 1275 & & & & & & & & & & & \\
\hline 1282 & & $\delta$ (N21-H23) & & & & & & & & & 1291 \\
\hline 1294 & $\mathrm{t}_{2}\left(\mathrm{NH}_{2}\right)$ & & & & 1297 & 1298 & 1297 & 1298 & 1297 & 1298 & \\
\hline & & & & 1309 & & & 1307 & 1307 & & 1308 & \\
\hline & & & 1312 & & 1312 & 1312 & 1312 & 1313 & 1312 & 1313 & 1313 \\
\hline & & & 1326 & 1326 & 1325 & 1326 & 1324 & 1325 & 1326 & 1326 & 1326 \\
\hline
\end{tabular}

put file contained the optimized structure, the Raman and IR intensities and frequencies, and the atomic displacements for each mode. At the optimized structure of the molecule, no imaginary frequency was obtained, proving that a true minimum of the potential energy surface was found.

In all spectra presented in this paper we use the conventional Porto notation $a(b c) d$, where $a$ and $d$ represent the directions of the incident and the scattered light and $b$ and $c$ represent the directions of polarizations of the incident and the scattered light. The scattering geometries in all figures are related to the irreducible representations of the factor group $C_{2}$ as follows: $x(y y) x, z(y y) z, y(x x) y, z(x x) z, x(z z) x$, $y(z z) y$ and $z(y x) z$ are from $A$ irreducible representation and $x(y z) x$ and $y(z x) y$ are from the $B$ irreducible representation.

Figure 2 presents the Raman spectra of LAHW for nine different scattering geometries in the spectral region $25-$ $225 \mathrm{~cm}^{-1}$ at room temperature. This region is known to have the lattice modes of the crystal $\left(\omega<200 \mathrm{~cm}^{-1}\right)$, although some internal modes can also be observed with low wavenumber, as occurs with the torsional vibration of $\mathrm{CO}_{2}$, $\tau\left(\mathrm{CO}_{2}\right)$, for $L$-asparagine monohydrated [9], $L$-valine [10] and $L$-isoleucine [11]. 


\begin{tabular}{|c|c|c|c|c|c|c|c|c|c|c|c|}
\hline \multirow{2}{*}{$\begin{array}{l}v(\mathrm{~cm}-1) \\
\text { Calculate }\end{array}$} & \multicolumn{2}{|c|}{ Base Set } & \multicolumn{9}{|c|}{ scattering geometries } \\
\hline & $6-311++G^{* *}$ & $6-311 G$ & x(yy)x & $\mathrm{z}(\mathrm{yy}) \mathrm{z}$ & $y(x x) y$ & $\mathrm{z}(\mathrm{xx}) \mathrm{z}$ & $\mathrm{x}(\mathrm{zz}) \mathrm{x}$ & $\mathrm{y}(\mathrm{zz}) \mathrm{y}$ & $\mathrm{x}(\mathrm{yz}) \mathrm{z}$ & $\mathrm{z}(\mathrm{yx}) \mathrm{z}$ & $\mathrm{y}(\mathrm{zx}) \mathrm{y}$ \\
\hline 1337 & $\mathrm{t}\left(\mathrm{CH}_{2}\right)$ & & 1341 & 1342 & 1341 & 1342 & 1340 & 1341 & 1340 & 1342 & \\
\hline \multirow[t]{3}{*}{1344} & & $\mathrm{t}\left(\mathrm{CH}_{2}\right)$ & 1349 & 1349 & 1349 & 1349 & 1348 & 1349 & 1348 & 1349 & \\
\hline & & & & & & & & & & & 1358 \\
\hline & & & 1371 & 1371 & 1370 & 1371 & & & 1370 & 1371 & 1389 \\
\hline 1388 & & $v(\mathrm{C} 2-\mathrm{C} 3)$ & 1388 & 1389 & 1389 & & 1390 & 1391 & & 1389 & \\
\hline \multirow[t]{4}{*}{1404} & $\delta\left(\mathrm{CH}_{2}\right)$ & & 1406 & & 1406 & 1406 & 1405 & 1406 & 1405 & 1406 & 1409 \\
\hline & & & 1439 & 1440 & 1440 & 1440 & 1438 & 1440 & 1439 & 1440 & 1440 \\
\hline & & & 1450 & 1450 & 1449 & 1450 & 1449 & 1450 & 1449 & 1450 & \\
\hline & & & 1456 & 1456 & 1456 & 1456 & 1455 & 1456 & 1455 & 1456 & 1457 \\
\hline 1474 & $\mathrm{r}\left(\mathrm{CH}_{2}\right)$ & & 1472 & 1474 & & 1472 & 1471 & & 1472 & 1473 & \\
\hline 1534 & & $\mathrm{w}\left(\mathrm{CH}_{2}\right)$ & 1535 & 1535 & & & & & & & 1535 \\
\hline 1572 & & $\delta\left(\mathrm{NH}_{3}\right) \mathrm{op}$ & & 1567 & 1565 & 1568 & 1564 & & & 1564 & 1566 \\
\hline \multirow[t]{2}{*}{1588} & $\delta(\mathrm{H}-\mathrm{N}-\mathrm{C})$ & $\delta(\mathrm{H}-\mathrm{N}-\mathrm{C})$ & & & 1591 & & & & & & \\
\hline & & & & 1605 & & 1605 & & & & 1604 & 1607 \\
\hline 1613 & $\delta$ (H10-C9-H11) & & & & & & 1614 & 1615 & & & \\
\hline 1623 & $\begin{array}{c}\delta \text { (H14-C12- } \\
\text { H13) }\end{array}$ & & 1619 & & 1622 & 1624 & & & 1621 & 1625 & 1621 \\
\hline \multirow[t]{11}{*}{1650} & $\begin{array}{c}\delta \text { (H18-C15- } \\
\text { H16) }\end{array}$ & $\begin{array}{c}\delta \text { (H14-C12- } \\
\text { H13) }\end{array}$ & 1654 & 1655 & & 1655 & 1655 & 1657 & 1652 & 1655 & \\
\hline & & & 2853 & 2854 & 2855 & 2854 & 2854 & 2854 & 2854 & 2854 & 2855 \\
\hline & & & 2879 & 2879 & 2879 & 2879 & 2879 & 2878 & 2879 & 2879 & 2878 \\
\hline & & & 2890 & 2891 & 2891 & 2891 & 2890 & 2890 & 2890 & 2891 & 2891 \\
\hline & & & 2904 & 2904 & 2904 & 2904 & 2905 & 2904 & 2904 & 2904 & 2904 \\
\hline & & & 2917 & 2918 & 2917 & 2917 & 2918 & 2917 & 2918 & 2918 & 2917 \\
\hline & & & 2944 & 2947 & 2943 & 2945 & 2940 & 2942 & 2944 & 2944 & 2944 \\
\hline & & & 2953 & 2954 & 2952 & & 2953 & & 2953 & 2953 & \\
\hline & & & 2962 & 2962 & 2962 & 2962 & 2962 & 2962 & 2962 & 2962 & 2960 \\
\hline & & & 2970 & 2970 & 2970 & 2971 & 2970 & 2970 & 2970 & 2970 & 2971 \\
\hline & & & 2991 & 2991 & 2991 & 2991 & 2991 & 2991 & 2991 & 2991 & 2991 \\
\hline \multirow[t]{2}{*}{3169} & & $v(\mathrm{C} 12-\mathrm{H} 14)$ & & & & 3176 & & & & & \\
\hline & & & 3179 & & & & 3183 & 3183 & 3181 & 3183 & 3183 \\
\hline \multirow[t]{5}{*}{3194} & & $\begin{array}{c}v(\mathrm{H} 16-\mathrm{C} 15- \\
\mathrm{H} 18)\end{array}$ & & & 3193 & & & & & & \\
\hline & & & 3335 & 3332 & & & 3335 & 3334 & 3336 & 3335 & 3332 \\
\hline & & & & & 3347 & 3344 & & & & & \\
\hline & & & & 3392 & 3391 & & & & & 3390 & 3398 \\
\hline & & & & 3482 & 3482 & 3481 & & & & 3483 & 3483 \\
\hline
\end{tabular}

Legend: $\delta$ = bending, $v$ = stretching, $\tau=$ torsion, $w=$ wagging, $t=$ twist, $r=$ rocking, ip = in plane, op = out of plane, skel. = framework vibration; subscripts indicate degenerence; superscript indicate same vibration for diferent atoms in same cluster. Atom numbering is shown in Figure 1.

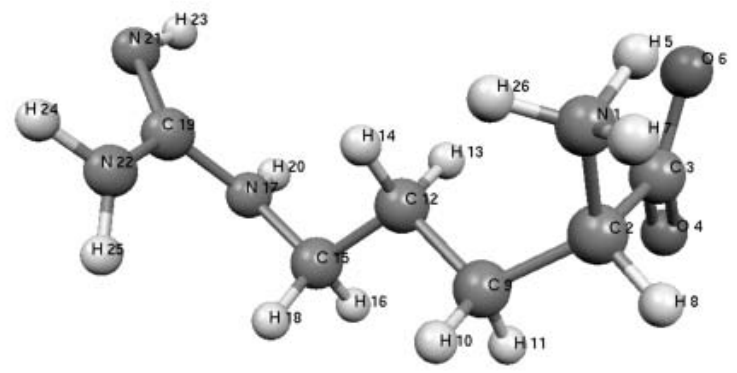

FIG. 1: Molecule of arginine in the zwitterion form.

In fact, the ab initio calculations performed in the present work show the occurrence of vibrations with $\omega<200 \mathrm{~cm}^{-1}$ that can be associated to internal modes. As an example, using the $6-311++G * *$ base set, it is possible to assign the in-plane torsion of $\mathrm{NH}_{3}^{+}, \tau\left(\mathrm{NH}_{3}^{+}\right) \mathrm{ip}$, as the mode appearing with wavenumber of $63 \mathrm{~cm}^{-1}$.

Related to the torsional vibration of $\mathrm{CO}_{2}^{-}, \tau\left(\mathrm{CO}_{2}\right)$, our calculations were not able to identify it precisely. However, it is possible to assign the band observed at $\sim 189 \mathrm{~cm}^{-1}$ as the $\tau\left(\mathrm{CO}_{2}\right)$. This is based on the studies performed on other hydrogenated amino acid crystals [9-11] as well as in deuterated one [12]. Such an assignment is important because under extreme conditions torsional vibrations of $\mathrm{CO}_{2}$ can present particular behavior and furnish insights about the hydrogen bonds, as those presented by $L$-alanine-d7 under pressure variation [13].

Fig. 3 presents the Raman spectra of LAHW for nine different scattering geometries in the spectral region $200-$ $650 \mathrm{~cm}^{-1}$. In this region it is found the bands associated to torsional vibration of $\mathrm{NH}_{3}^{+}, \tau\left(\mathrm{NH}_{3}^{+}\right)$. In general, the band associated to this vibration has a low intensity, at least as 


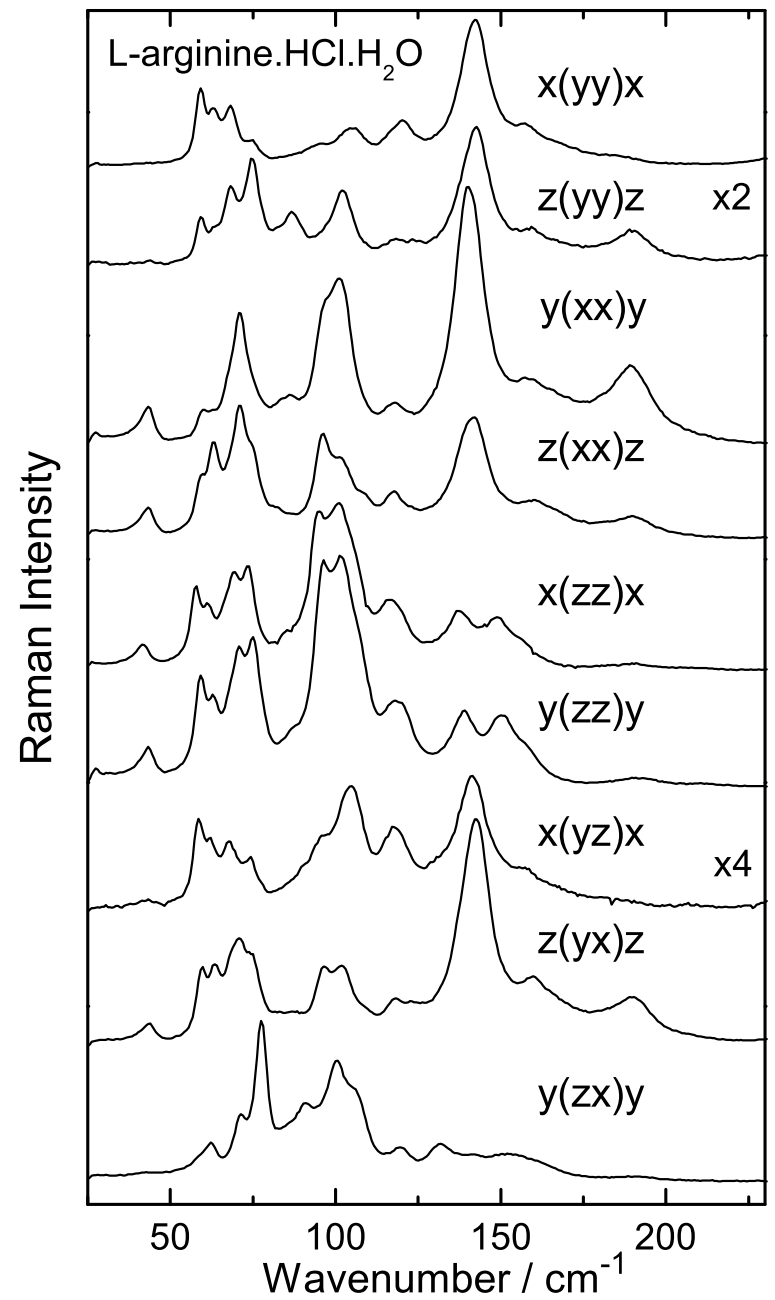

FIG. 2: Raman spectra of $L$-Arginine hydrochloride monohydrate crystal in several scattering geometries in the $25-225 \mathrm{~cm}^{-1}$ spectral region.

suggested by former works on $L$-alanine [12] and $L$-leucine [14]. Other important vibration is associated to the rocking of $\mathrm{NH}_{2}, r\left(\mathrm{NH}_{2}\right)$, which ab initio calculations show to be between 445 and $465 \mathrm{~cm}^{-1}$. Bending vibration of $\mathrm{NH}$ are also found in this spectral region, at about $530 \mathrm{~cm}^{-1}$, while the bending of $N-C-N, \delta(N C N)$, was identified as the peak at $\sim 551 \mathrm{~cm}^{-1}$, a band with small linewidth as can be observed in Fig. 3 for some scattering geometries.

Fig. 4 presents the Raman spectra of LAHW in the spectral region $650-1750 \mathrm{~cm}^{-1}$ for nine different scattering geometries. This region presents a series of bands and the $a b$ initio calculation was fundamental to assign in a most precise manner. The peak observed at about $678 \mathrm{~cm}^{-1}$ was associated to a $C 2-C 3$ stretching vibration, $v(C 2-C 3)$. Here we need to state the following observation: both, $C 2$ and $C 3$ carbon atoms are hold with other atoms $\left(\mathrm{NH}_{3}\right.$ for $\mathrm{C}_{2}$ and $\mathrm{O}_{2}$ for $C 3$ ) in such a way that we do not have a $C-C$ "pure" vibration, as occurs with diamond; this explains why for diamond the $v(C-C)$ vibration is observed at $1332 \mathrm{~cm}^{-1}$. A wagging vibration related to the $N-C-N$ unit was associated to the band observed at $751 \mathrm{~cm}^{-1}$. The bending of $\mathrm{CO}_{2}^{-}$unit,

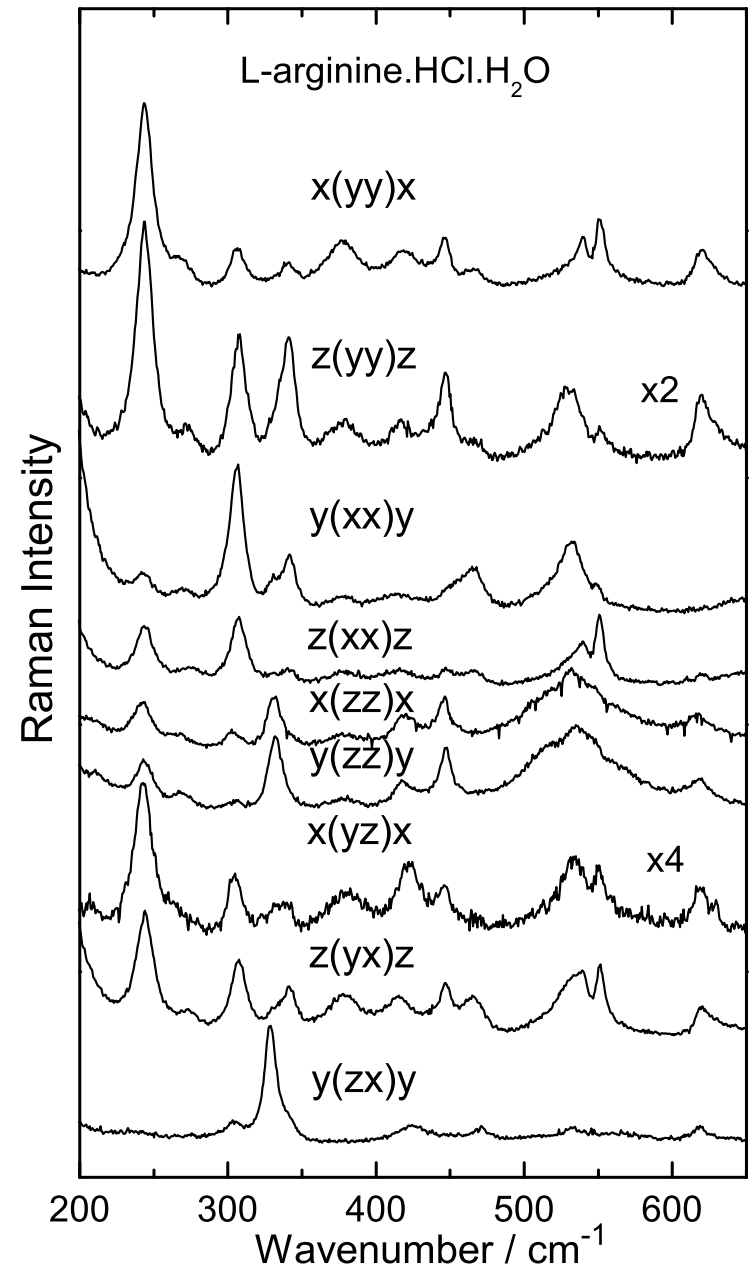

FIG. 3: Raman spectra of $L$-Arginine hydrochloride monohydrate crystal in several scattering geometries in the $200-650 \mathrm{~cm}^{-1}$ spectral region.

$\delta\left(\mathrm{CO}_{2}^{-}\right)$, was observed at $843 \mathrm{~cm}^{-1}$, as pointed out by our calculations. The bands observed at about 930 and $940 \mathrm{~cm}^{-1}$ were associated to the wagging vibration of $\mathrm{NH}_{2}, w\left(\mathrm{NH}_{2}\right)$. The stretching vibration of $C 2-N 1, v(C 2-N 1)$, was associated to the band observed at $\sim 1052 \mathrm{~cm}^{-1}$, and an out-ofplane $\mathrm{NH}_{3}^{+}$rocking vibration, $r\left(\mathrm{NH}_{3}^{+}\right)$, was assigned as the band observed at about $1090 \mathrm{~cm}^{-1}$. An out-of-plane $\mathrm{NH}_{3}^{+}$ vibration was assigned as the band observed at $\sim 1250 \mathrm{~cm}^{-1}$.

Many bands are observed between 1300 and $1400 \mathrm{~cm}^{-1}$, among them the twist vibration of $\mathrm{CH}_{2}, t\left(\mathrm{CH}_{2}\right)$. It is worth to note that the $6-311 \mathrm{G}$ basis of calculation suggests that the $C 2-C 3$ stretching vibration should be observed at $1388 \mathrm{~cm}^{-1}$. However, because the reason given previously (carbon atoms bonded to other atoms) we believe that the suggestion is not correct. The band observed at $1406 \mathrm{~cm}^{-1}$ was associated with the bending vibration of $\mathrm{CO}_{2}^{-}, \delta\left(\mathrm{CO}_{2}^{-}\right)$, and a rocking vibration of the same unit, $r\left(\mathrm{CO}_{2}^{-}\right)$, was associated to the band observed at $\sim 1472 \mathrm{~cm}^{-1}$. Finally, in this spectral region we also observed bending vibrations of the $H-N-C$ unit, between 1600 and $1650 \mathrm{~cm}^{-1}$. 


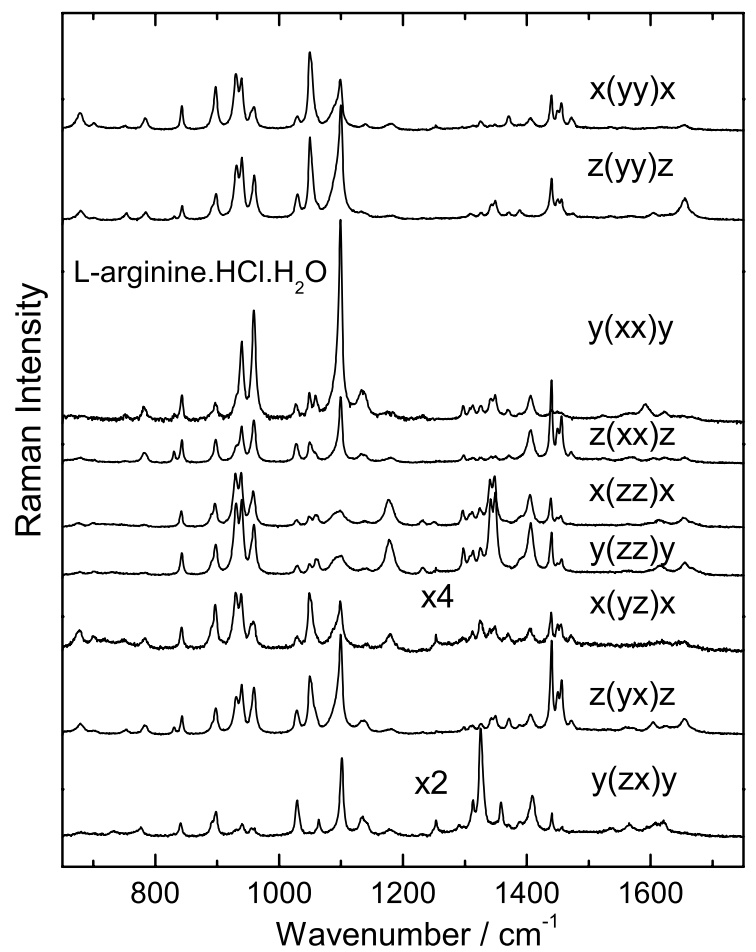

FIG. 4: Raman spectra of $L$-Arginine hydrochloride monohydrate crystal in several scattering geometries in the $650-1750 \mathrm{~cm}^{-1}$ spectral region.

Fig. 5 presents the Raman spectra of LAHW crystal in the spectral region $2800-3600 \mathrm{~cm}^{-1}$ for nine different scattering geometries. The profile between 2800 and $3000 \mathrm{~cm}^{-1}$ is very rich, originated mainly from stretching vibrations of $\mathrm{CH}$. However, our calculations were not able to assign separately all bands in this region. Finally, the bands with high linewidths centered at $\sim 3200 \mathrm{~cm}^{-1}$ and $3400 \mathrm{~cm}^{-1}$ can be associated to the stretching vibration of water, $\mathrm{v}\left(\mathrm{H}_{2} \mathrm{O}\right)$, as it is expected from crystals with structural water [15].

With this assignment we can both (i) through light on the phase transition undergone by LAHW at low-temperatures and (ii) to give insights on future works on vibrational properties of the crystal under high pressure conditions. Related to the first point we remember that Raman spectroscopy study have suggested the occurrence of a phase transition undergone by LAHW crystal at about $110 \mathrm{~K}$ [8]. This phase transition was inferred mainly by the change of band profiles in the low-wavenumber region of the spectra. Obviously, as stated previously, these modifications are associated with lattice mode vibrations. Interesting enough is that we have also observed modifications in bands observed at $1088-1100 \mathrm{~cm}^{-1}$. The assignment of the present study confirms the identification of such bands as rocking vibrations of $\mathrm{NH}_{3}$ units. In other words, our study reinforces the interpretation that the low temperature phase transition undergone by LAHW can be understood mainly as conformational change of the $L$-arginine molecules, mainly consequence of modifications on hydrogen bonds $N-H \ldots O$, with the oxygen atom belong to a water molecule or to the $\mathrm{COO}-$ group

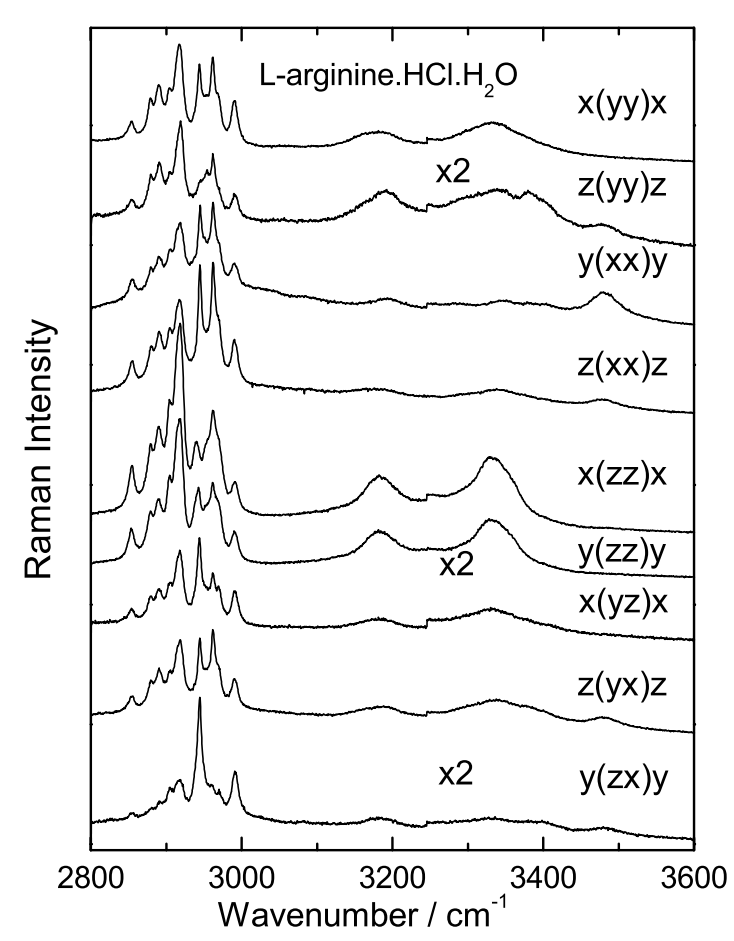

FIG. 5: Raman spectra of $L$-Arginine hydrochloride monohydrate crystal in several scattering geometries in the $2800-3600 \mathrm{~cm}^{-1}$ spectral region.

of another arginine molecule. This is in good accordance with experimental facts already presented by $L$-cisteine [16] and $L$-serine [17] crystals when submitted to high pressure conditions - the change of molecular conformation, due to variations in the dimensions of hydrogen bonds, modifies the symmetry of the unit cell of the crystal.

\section{Conclusions}

In this paper we presented the polarized Raman spectra of LAHW in the spectral region between 25 and $3600 \mathrm{~cm}^{-1}$. $\mathrm{Ab}$ initio calculations were used to assign most of the bands observed in all nine scattering geometries. With such identification we gave insights about a previously observed phase transition undergone by LAHW at low temperatures. Finally, the work will be useful to understand eventual modifications in the Raman spectra of LAHW, for example, when submitted to high pressure conditions in future works.

\section{Acknowledgments}

The authors acknowledge CNPq, CAPES and FUNCAP for partial financial support. The authors also acknowledge Dr. J.M. Sasaki for X-ray diffraction measurements and CENAPAD-SP for the use of the GAUSSIAN 98 software 
package and for computational facilities through the project

reference "proj373".

[1] K. Seguro, T. Tamiyam, T. Tsuchiya, J.J. Matsumoto, Cryobiology 27, 70 (1990).

[2] M. Mumenthaler, C.C. Hsu, R. Peralman, Pharm. Res. 11, 12 (1994).

[3] C.C. Hsu, H.M. Hguyen, D.A. Yeung, D.A. Brooks, G.S. Koe, T.A. Bewlwy, R. Pearlman, Pharm. Res. 12, 69 (1994).

[4] T. Arakawa, K. Tsumoto, Biochem. Biophys. Res. Commun. 304, 148 (2003).

[5] S.B. Monaco, L.E. Davis, S.P. Velsko, F.T. Wang, D. Eimerl, A. Zalkin, J. Crystal Growth 85, 252 (1987).

[6] S. Hausshe, J. Chrosch, F. Gnanam, E. Fiorentini, K. Recker, F. Wallrafen, Cryst. Res. Technol. 25, 617 (1990).

[7] S. Mukerji, T. Kar, Mater. Chem. Phys.57, 72 (1998).

[8] R.J.C. Lima, P.T.C Freire, J.M. Sasaki, F.E.A. Melo, J.Mendes Filho, J. Raman Spectrosc. 33, 625 (2002).

[9] A.J.D. Moreno, P.T.C. Freire, I. Guedes, F.E.A. Melo, J.M. Filho, J.A. Sanjurjo, Braz. J. Phys. 29, 380 (1999).

[10] J.A. Lima Jr., P.T.C. Freire, R.J.C. Lima, A.J.D. Moreno, J.M.
Filho, F.E.A. Melo, J. Raman Spectrosc. 36, 1076 (2005).

[11] F.M. Almeida, P.T.C. Freire, R.J.C. Lima, C.M.R. Remdios, J.M. Filho, F.E.A. Melo, J. Raman Spectrosc. 37, 1296 (2006).

[12] H. Susi, D.M. Byler, J. Mol. Struct. 63, 1 (1980).

[13] J.M. Sousa, P.T.C. Freire, H.N. Bordallo, D.N. Argyriou, J. Phys. Chem. B 111, 5034 (2007).

[14] P.F. Façanha Filho, P.T.C. Freire, K.C.V. Lima, J. Mendes Filho, F.E.A. Melo, P.S. Pizani, Braz. J. Phys. 38, 131 (2008).

[15] A.J.D. Moreno, P.T.C.Freire, I. Guedes, F.E.A. Melo, J. Mendes Filho, J.A. Sanjurjo, Braz. J. Phys. 29, 380 (1999).

[16] V.S. Minkov, A.S. Krylov, E.V. Boldyreva, S.V. Goryainov, S.N. Bizyaev, A.N. Vtyurin, J. Phys. Chem. B 112, 8851 (2008).

[17] E.V. Boldyreva, H. Sowa, Yu. V. Seryotkin, T.N. Drebushchak, H. Ahsbahs, V. Chernyshev, V. Dmitriev, Chem. Phys. Lett. 429, 474 (2006). 